\title{
Os registros da Polícia e seu aproveitamento para a História do Rio de Janeiro: Escravos e Libertos*
}

\author{
Leila Mezan Algranti
}

Os códices da intendência da polícia existentes no arquivo Nacional são fontes importantes para o estudo do Rio de Janeiro e abrangem um período significativo da história da cidade, desde a fundação da Intendência em 1808 até meados do século XIX (1). Os documentos fornecem elementos para a compreensão da vida social e econômica da capital do país e da Província do Rio de Janeiro.

Trata-se de uma vasta coleção de manuscritos, alguns em precário estado de conservação, outros razoavelmente restaurados. Não há notícias de que tenham sido publicados ou relacionados em índices discriminativos. A única informação possível são os catálogos do próprio arquivo.

Os códices constituem-se de séries da correspondência dos intendentes da polícia com diversas autoridades, dentre elas juízes de crimes dos bairros da corte, ministro de Estado e presidentes de outras províncias. Constam ainda desses códices registros específicos sobre escravos, como por exemplo despesas com escravos fugidos, registros de punições de cativos e relações de prisões feitas pela polícia na corte do Rio de Janeiro (2).

$\mathrm{O}$ acesso e manuseio desses documentos é bastante simples, com exceção de alguns códices que se encontram disponíveis apenas em microfilmes. Há alguns problemas quanto às datas dos documentos, que muitas de 1982

(*) - Trabalho apresentado no $5^{\circ}$ Congresso de Arquivologia, em outubro

(1) - A Intendência da polícia do Brasil foi criada à imagem da existente em Portugal, como muitas das instituições que D. João organizou após a sua chegada. A 10 de maio do mesmo ano criou-se também o cargo de intendente geral da Polícia. Roberto Macedo. Paulo Fernandes Viana, Administração do Primeiro Intendente, Rio de Janeiro, 1956 pp. 18-19.

(2) - A relação do sdocumentos da Polícia do Rio de Janeiro refeerntes ao período joanino e consultados por nós encontra-se discriminada no final deste artigo. 
vezes não conferem com aquelas estampadas nas capas, nem conseqüentemente com as existentes nos catálogos.

Esses documentos, avaliados como um todo, possibilitam estudos sobre o desenvolvimento econômico da cidade, acerca de problemas de abastecimento e monopólios comerciais e relações econômicas com outras províncias. São de grande valia nas pesquisas sobre o comércio interno da capital.

Em termos de dados para a história política, contêm declarações im. portantes, podendo-se captar o discurso da camada dominante e dos representantes governamentais sobre questões de defesa, relações com estrangeiros, além de posturas referentes às diversas camadas sociais.

Para o estudo social, que particularmente nos interessa, permitem que sejam selecionadas informações sobre grupos sociais específicos, por exemplo escravos, libertos, mulheres e clérigos, além de representarem fonte indispensáveis para a análise do aparelho repressor da cidade.

Quanto ao aproveitamento real desses manuscritos já foram utilizados na elaboração de uma dissertação de mestrado: Feitor Ausente estudo sobre a Escravidão Urbana no Rio de Janeiro, e num estudo quantitativo sobre Padrões de criminalidade escrava no Rio de Janeiro joanino.

Para esta comunicação, foram selecionados alguns documentos que permitiram uma análise das relações de conflitos existentes entre escravos e forros, bem como de escravos entre si, na cidade do Rio de Janeiro entre 1808 e 1822 .

Antes de comentar o caráter desses antagonismos, faz-se necessário algumas considerações breves sobre a cidade do Rio de Janeiro no período estudado e o papel dos escravos nesse centro urbano, assim como o funcionamento da escravidão nas cidades.

\section{CRESCIMENTO POPULACIONAL E DESENVOLVIMENTO DO RIO DE JANEIRO}

Durante o período joanino, a cidade do Rio de Janeiro sofreu alterações profundas no seu aspecto físico e econômico, como na composição de sua população. A transferênca da corte para o Brasil transformou o Rio de Janeiro no centro de decisões políticas e económicas, e no principal porto do país. A abertura dos portos e consequiente fim do monopólio estimularam as atividades econômicas e a criação de novos setores de serviços (3).

(3) - Entre 1808 e 1822 a área da cidade quase que triplicou. Entretanto a falta de marcos precisos entre os limites urbanos e rurais, e o fato da cidade crescer 
O crescimento e o desenvolvimento da cidade encontram-se sem dúvida intimamente ligados ao aumento populacional estimulado pela vinda da família Real. Além dos indivíduos ligados ao comércio, corpo diplomático e burocrático nota-se um movimento migratório interno da colônia, de pessoas que procuravam novas oportunidades na capital do império. O aumento no tráfico negreiro também é digno de atenção. Após 1809 o volume do tráfico aumentou sensivelmente (4), devido à crescente necessidade de mão-de-obra provocada pelas novas oportunidades que se abriam para a utilização dos escravos (5).

A falta de censos e estimativas exatas para o período colonial dificultam a avaliação do aumento populacional da cidade entre 1808 e 1822 . Os dados mais aproximados parecem ser aqueles fornecidos por Luccock e pelo censo de 1821. Entretanto, ambos sugerem cálculos abaixo do real e devem portanto ser encarado com reservas. Segundo esses cálculos, a população teria crescido em $32.2 \%$ no período estudado. (6)

Como nas demais cidades brasileiras da época, grandes massas de escravos concentravam-se no Rio de Janeiro, fenômeno que não poderia deixar de existir numa cidade que vivia basicamente da economia escravista (7).

O impacto do volume do tráfico na população da cidade e principalmente na sua composição racial é perfeitamente sentido na documentação da polícia e nos registros de contemporâneos. Os negros (escravos e libertos), além de constituírem a maior parte da população, encontravam-se em todos os locais a qualquer hora do dia; nos mercados, ruas, bares, trabalhando ou apenas circulando pela cidade. Tornavam-se dessa forma cbjeto de atenção especial da polícia, que procurava estabelecer medidas de controle sobre essa camada da população, promulgando leis que cerceavam, embora não proibissem, a mobilidade dos negros (8).

de forma acelerada, dificultam a circunscrição precisa do perímetro urbano. Dado esse fato, a área da cidade considerada para esse estudo é aquela que a cidade apresentava no final do período (1822).

(4) - Herbert Klein, The Middle Passage, Princeton, 1978, p. 54.

(5) - Até 1809 a quantidade de escravos que chegava à cidade variava entre 5.839 e 10.536 anuallmente. Após esta data houve um constante aumento que chegou a atingir 34.000 escravos por volta dos anos vinte. Cf. Herbert Klein, op. cit., p. 54.

(6) - Vide Tabela sobre a população da cidade no final do Trabalho.

(7) - Clark Abel estimou que $3 / 4$ da população da cidade seria composta de negros em 1816. Narative of a Journey in the interior of China to and from that country in the years of 1816-1817. Londres, 1819. p. 15.

(8) - Pelo edital de 6-12-1816 — os escravos encontrados armados seriam punidos com 300 açoites, Cod 323, vol. 6, pp. 35-36., (11-11-1820). ANRJ. O Toque de Recolher destinava-se à população escrava e liberta que deveria respeitá-lo, não podendo permanecer pelas ruas após às 8 horas da noite. 
A liberdade de movimentos vivenciada pelos escravos nas cidades algo amplamente comentado pelos estudiosos do escravismo moderno, a característica fundamental da escravidão urbana.

\section{Escravidão e Cidade}

A escravidão adaptava-se ao ambiente urbano ao mesmo tempo em que adquiria feições próprias, necessárias a sua sobrevivência. A instituição que se desenvolveu nas cidades diferia em aspectos essenciais daquela existente no mundo rural, embora se tratasse do mesmo fenômeno e mantivesse portanto seus princípios básicos.

Embora um grande número de escravos se dedicasse às tarefas domésticas e tivesse um contato intenso com seus senhores, muitas outras ocupações ficavam a cargo deles. As funções de sapateiro, alfaiate, carpinteiro, carregador, enfim, todos os serviços, especializados ou não, eram efetuados pelos cativos que supriam a demanda de mão-de-obra causada pelo desenvolvimento das economias urbanas. Os escravos, dado ao tipo de trabalho que efetuavam, passavam grade parte de seu tempo longe do controle do senhor, ocupados em diversas atividades externas. Esse enfraquecimento da disciplina rígida e a ausência do domínio total do senhor sobre sua propriedade, induziram à conclusão de que a vida nas cidades levava ao afrouxamento dos laços servis e acabava por alterar as relações senhor-escravo. (9)

As formas de trabalho escravo desenvolvidas na cidade - sistemas de ganho e aluguel - levaram a escravidão além dos estreitos confinamentos da relação senhor-escravo. Ao sair ao ganho pelas ruas em busca de trabalho, ou alugados a outros proprietários, os negros entravam em contato com indivíduos das diversas camadas da sociedade, estabelecendo relações inexistentes no mundo rural, e estreitando seu relacionamento com os demais escravos da cidade.

As cidades produziam, assim, efeitos definitivos tanto na instituição da escravidão - no seu funcionamento e organização - como na vida dos escravos. Se nos dizeres de Florestan Fernandes a sociedade escravista vivia sobre um vulcão, poderíamos acrescentar que, na cidade, ele entrava em erupção com facilidade. A vida nas cidades provocava diariamente um conjunto de situações inesperadas, às quais os escravos, como os demais indivíduos, precisavam se acomodar. As relações que se estabeleciam entre os indivíduos eram naturalmente afetadas por todo esse ambiente que os circundava. Relações de conflitos e solidariedade adquiriam cono-

(9) - Cf. Richard Wade. Slavery in the Cities - The South 1820-1860: Londres, 1977, p. 48. 
tações próprias do ambiente urbano, determinadas pelo maior ou menor peso dos elementos externos à situação clássica senhor-escravo.

Entretanto, oprimidos e discriminados de todos os lados, era com os libertos e com seus semelhantes que os escravos estabeleciam maior contato. Juntos cultuavam suas divindades, praticavam seus ritos e feitiços. Era entre si, que ruminavam seus ódios, planejavam suas revoltas, constituíam suas famílias e se divertiam.

A uma relação tão estreita só restava dar voltas em si mesma, convertendo-se em fonte de energia e manutenção e também de auto-destruição. Os momentos de tensão eram portanto tão frequentes quanto os de amizade e cooperação. Não raro estoụravam brigas, desavenças e inimizades entre a população de cor, causadas por ciúmes e vinganças. Não só contra os brancos descarregavam sua insatisfação e frustrações. A relação entre escravos e forros, e escravos entre si, era tensa e repleta de desconfiança. Muitas revoltas de escravos abortaram devido à falta de união de seus idealizadores e por delações vindas dos próprios cativos e libertos.

Como destacou Russell-Wood, "com exceção das companhias de milícias e das irmandades religiosas, elas mesmas não totalmente livres de divisões internas, a população livie de cor caracterizou-se pela falta de solidariedade e de coesão" (10). Ao analizar os registros da polícia do Rio de Janeiro, o estudioso percebe uma série infindável de crimes e atentados praticados no interior da camada escrava, e a ausência de movimentos de massa dos cativos. Isso não significa que os escravos do Rio de Janeiro fossem mais pacíficos ou assimilados; quer dizer apenas que desenvolviam outras formas de contestação ao regime, na maior parte das vezes ações individuais ao seu alcance. Os crimes e fugas foram as formas mais típicas de reação ao sistema que os oprimia, como demonstra o estudo dos padrões de criminalidade escrava no Rio de Janeiro.

Não é nosso objetivo discutir aqui a ação dos escravos contra o regime escravista. Vários estudos recentes têm se preocupado com o assunto (11). O que cabe destacar, entretanto, é um outro aspecto das relações sociais desenvolvidas pelos escravos urbanos: as relações de tensão existentes entre os indivíduos das camadas inferiores da sociedade. Não se trata de privilegiar as relações de conflito existentes entre escravos e forros, escravos entre si. Pretende-se apenas revelar o outro lado da questão que tem em geral permanecido encoberto.

(10) - Russell-Wood "Colonial Brazil" in David Cohen and Jack Breene Neither Slave Nor Free, Baltimore, 1972, p. 130.

(11) - Veja-se por exemplo Alipio Goulart, Da fuga ao Suicídio, aspectos de Rebeldia dos escravos no Brasil, R. J., 1972. Suely de Queiroz., Escravidão Negra em São Paulo, Rio, 1977. 


\section{RELAÇÕES DE CONFLITO ENTRE ESCRAVOS E FORROS NO RIO DE JANEIRO}

Os forros como grupo social específico, têm sido geralmente estıdados com o objetivo de melhor se compreender as relações sociais que se desenvolveram no Brasil, particularmente entre brancos e negros. Pouco se tem dito sobre as relações entre escravos e forros embora sejam fundamentais para a compreensão da vida dos escravos no meio urbano. O exemplo do Rio de Janeiro joanino certamente contribuirá para esclarecer alguns aspectos desse relacionamento.

A partir do século XVIII, acentuou-se o crescimento da população de cor livre no Brasil, sendo isto considerado um fenômeno desse período.

A crescente urbanização, a descoberta das minas e as condições sócioeconômicas próprias à cidade e estranhas ao ambiente rural estimularam o aumento do número de libertos. Durante todo o século XIX, mantevese o vigoroso crescimento dessa camada da população, que segundo Herbert Klein, teria sido a que apresentou maior índice de expansão no decorrer do século (12).

Novamente a falta de dados estatísticos dificulta a análise do número de forros, tanto no Rio de Janeiro como no resto do país. Sabemos entre. tanto que em 1797 viviam na corte 8.812 negros livres (37\% da população de cor). Luccock avaliou-os em apenas mil em 1808 (13) e Mary Karash por sua vez estimou que por volta de 1849 significariam 5\% da população da cidade do Rio de Janeiro (14).

Apesar dos dados contraditórios, a presença dos libertos pocle ser notada de forma acentuada através dos livros da polícia. Somente nos registros de prisões ocorridas na corte entre 1810 e 1821, 9.444 forros foram enviados para o Calabouço, constituindo $20 \%$ das prisões efetuadas ná cidade.

Não se pretende discutir nesse artigo a origem desses indivíduos no Rio de Janeiro, nem tampouco o processo de manumissão em si mesmo. No momento, cabe destacar que durante todo o período estudado intensificou-se o número de libertos na cịdade, tanto devido às manumissões adquiridas pelos escravos locais como através da chegada de libertos de outras

(12) - Herbert Klein estimou que 40 a $60 \%$ do total da população de côr do país era composta de homens livres, "Ninettenth Century Brazil in: David Cohen and Jack Greene, Neither Slave, Nor Free, Baltimore, 1972, p. 316.

(13) - John Luccok. Notas sobre o Rio de Janeiro e partes meridionais do Brasil. Belo Horizonte, 1975 , p. 28.

(14) - Mary Karasch. Slavery in Rio de Janeiro e partes meridionais do Brasil, Belo Horizonte, 1975, p. 28. 
partes do país. O ambiente urbano atraía os forros por oferecer oportunidades de trabalho, ainda que precárias. Eram aproveitados $\mathrm{em}$ tarefas típicas de escravos- ou como feitores, capitães do mato e capatazes. Des. tacavam-se também no artesanato como aprendizes, ou dedicavam-se a trabalhos esporádicos, sendo a vadiagem e a mendicância muitas vezes sua última opção.

Associados aos escravos pela camada dominante, devido às semelhanças físicas e às ligações que mantinham com os cativos, eram tratados pelos órgãos repressores da mesma forma como os escravos. Como destacou Russell-Wood, os libertos eram prejudicados por uma legislaçäo "que frequentemente fracassou em distinguir escravos de homens livres" e que se baseava em preceitos étnicos (15).

Os libertos eram temidos pela sociedade carioca não apenas por suas ligações com os escravos, mas também como indivíduos que, levados pela necessidade praticavam furtos e outros crimes, ameaçando a população branca. Grande parte da atenção das rondas, recaía sobre eles. Desordens, bebedeiras, assaltos, eram freqüentes no Rio de Janeiro. Dentre os crimes praticados pelos forros destacam-se os furtos, 30\% (267), e os atos 'de violência, que também representavam $30 \%$ das prisões feitas na corte no período estudado. Grande parte desses crimes foram cometidos contra seus semelhantes e contra os escravos.

Se por um lado os forros se identificavam com os escravos em muitas situações, e desenvolviam laços de solidariedade, estimulados pelo sistema escravista que dificultava a mobilidade social do ex-escravo, por outro as situações de conflitos não eram menos comuns. A vida dos libertos era totalmente desequilibrada. Ora empregados, ora vadios, enfrentando constantemente a fome e a miséria, encontravam no crime, nas brigas e desordens uma válvula de escape, uma solução para seus problemas. Muitas vezes ao invés de se revoltarem contra os representantes e defensores do regime, faziam dos escravos e de seus próprios semelhantes as vítimas de sua violência. Afinal era o sistema escravista que os empurrava para elas, através de um contato quase imposto.

Os antagonismos existentes entre escravos e forros podem ser classificados de maneira geral em conflitos contra a pessoa física e sua propriedade e questões de caráter moral. No primeiro caso, manifestavam-se na forma de disputas e crimes, e no segundo em atitudes ou padrões de comportamento.

Encontram-se nos livros de polícia vários casos de roubos ou atentados praticados por libertos contra escravos, e de escravos contra liber-

(15) - Russell Wood op, cit., p. 109. 
tos. Paulo de Castro, forro, por exemplo, foi levado para a prisão por roubar a preta Mequelina. Ao mesmo sucedeu ao pardo forro José Cardoso ao ferir com facadas e roubar o escravo crioulo de Joaquim Dias (16). Os motivos específicos que levavam a esses crimes não são registrados pela polícia na maior parte dos casos. Sabe-se entretanto que muitos deles eram crimes passionais, como o cometido por Francisco Antonio, pardo forro que matou com pancadas no nariz, seu rival, um escravo crioulo (17). Alguns chegavam a assassinar um companheiro por pequenas disputas. Alexandre preto forro, tentou matar seu colega por faltar ao pagamento do aluguel (18).

Além das desavenças corriqueiras (brigas, cabeçadas, pancadas) e das agressões violentas, escravos e libertos envolviam-se em questões morais que comprovam o clima de desarmonia reinante, como por exemplo a posse de cativos, denúncias, e roubo de escravos. Não era raro entregarem escravos fugidos à capitães do mato, ou ir vendê-los fora dos limites da cidade (19) .

Não havia realmente escrúpulos ou razões raciais mais fortes, quando a questão era sobreviver numa sociedade competitiva que os oprimia e Thes obstruía os caminhos da mobilidade social. A idéia de que o forro sempre se colocava ao lado do escravo é questionável. Havia sem dúvida uma certa identificação, mas muitas vezes o liberto, pela condição de livre, aliava-se à camada dominante na esperança talvez de se integrar nessa ordem social que the era tão hostil. Assim se explica o grande numero de capitães do mato e de feitores libertos, que funcionavam como agentes do sistema que anteriormente os subjugara.

Se tomarmos como indicador os números fornecidos pelos registros de prisões no Rio de Janeiro, notaremos que $71.9 \%$ dos escravos pıesos pelas rondas eram africanos e que $94.4 \%$ dos prisioneiros libertos eram crioulos, pardos ou preto. Não sabemos qual o significado exato dessas proporções em relação à população geral da cidade, mas são porcentagens demasiado importantes para passarem desapercebidas. Talvez o grande número de disputas existentes entre libertos e escravos no Rio de Janeiro encontre uma explicação nas rivalidades de nações, uma vez que a maior parte dos forros era crioula (nascida no Brasil) e dos escravos era africana.

(16) - Cod. 330, vol. 2, 10-05-1822. ANRJ .

(17) - Cod. 330, vol. 4, s/p ANRJ.

(18) - Cod. 403, vol. 3, 131 30-10-1818. ANRJ .

(19) - Dois cabras forros foram presos no Rio de Janeiro por "pegarem em pretos com o título de fugidos e os irem vender a capitães do mato" Cod. 403, V. 2 , p. $368-9-8-1820$. ANRJ. 


\section{RELAÇOEES DE CONFLITOS ENTRE ESCRAVOS NO RIO DE JANEIRO}

O aumento da população escrava no Rio de Janeiro após a primeira década do século XIX e os fatores que o estimularam já foram assinalados na primeira parte desse trabalho. Contudo, é preciso frisar que como con. sequência desse fenômeno foram reforçadas as medidas de controle da população negra, principalmente devido à ameaça que o grande contingente de escravos representava para a tranquilidade da camada dominante da sociedade.

Controlados com grande ímpeto quer pelo feitor, quer pelo senhor, quer pela polícia, era entre si que os escravos acabavam por encontrar maior apoio e cooperação. O excesso de fiscalização e dominaçâo do regime escravista, por sua vez, deixava pouco espaço para os escravos agirem contra ele. Grande número de escravos descarregavam sua agressividade e insatisfação em seus próprios companheiros de cativeiro.

Pequenas desavenças convertiam-se com frequiência em crimes de maior porte devido à presença de uma arma, ou simplesmente pela agilidade e rapidez de um golpe de capoeira. O alto índice de alcoolismo entre os negros também era responsável por essa perda de controle, que os levava a cometerem ações, das quais muitas vezes não se recordavam quando sóbrios. As disputas existentes entre negros de nações diferentes contribuiam ainda mais para os momentos de conflitos. Essas diferenças, ao invés de serem minimizadas e controladas pelos senhores, eram utilizadas como estratégia pela camada dominante na esperança de desuní-los mais. Costumava-se evitar numa mesma propriedade a concentração de escravos provenientes de uma mesma região da África, ou então o excesso de crioulos. Nas cidades esse controle era praticamente impossível devido à facilidade de se encontrarem fora das casas de seus senhores. Não faltaranı entretanto, crimes cometidos entre escravos de uma mesma nação. Até contra maridos, esposas, e amantes agiam sem pestanejar. André Vieira, pardo escravo, foi condenado a duzentos açoites aflitivos, e a degredo por toda vida para galés de Angola pelo crime de ter matado sua parceira Francisca parda (20).

Entre 1809 e 1822, os intendentes da polícia não pararam jamais de apontar e exigir providências contra os crimes ocorridos na cidade, grande parte deles cometidos por escravos contra seus semelhantes, quase sempre habitantes do perímetro urbano (21).

(20) - Caixa 219, Pac. 1, doc. 35, 1820.

(21) - Veja-se por exemplo o trecho de uma carta de Paulo Fernandes Viana ao Juiz de Crime de Bairro da Candelária: "Pelos ferimentos feitos de noite em André escravo (...) provocada V. mce. a corpo de delito e devassa. Por esta 
Muitos desses crimes (atentados, furtos, homicídios) ocorriam à noite por ser o momento em que os negros dispunham de maiores oportunidades para se encontrarem sem a presença dos brancos. Por exemplo, Antonic, escravo Cabinda, foi preso por facadas dada à noite em um escravo de José Alves de Azevedo (22).

Dentre os crimes praticados pelos escravos contra seus companheiros destacavam-se os atentados à faca e navalha, - armas mais difundidas entre os negros - que causavam na maior parte das vezes, de acordo com os registros, apenas alguns ferimentos. Entretanto, nota.se uma série de homicídios sem maiores esclarecimentos cujas vítimas eram escravos da cidade, desconhecendo-se os agressores. Os corpos apareciam jogados nas rias ao amanhecer, intrigando os agentes da polícia e os habitantes da corte.

$\mathrm{O}$ índice de violência na cidade do Rio de Janeiro era bastante alto, crescendo nos últimos anos do período. Dos 5.078 casos de prisões efetuadas pela polícia, $80 \%$ eram de escravos, sendo que a proporção das vítimas que viviam no cativeiro e sofreram agressões físicas representava aproximadamente $60 \%$ do total (23). Os números fornecidos pelos documentos da polícia esclarecem o papel dos escravos dentre os criminosos na cidade, revelando também que era entre eles que encontravam suas vítimas.

Além das agressões físicas e dos furtos ocorridos entre escravos, o clima de tensão existente manifestava-se através de certas atitudes no seu comportamento. Não deixa de ser um ato de violência, um escravo subjulgar um elemento de sua própria raça ao cativeiro, reforçanclo dessa forma o sistema que tanto o oprimia. Entretanto, não era um fato raro, escravos comprarem negros boçais e treiná-los para serem seus ajudantes. Nos casos de disputas entre escravos e senhores que chegavam à intendência da polícia sobre questões de manumissão, nota-se com clareza esse fenômeno. Os negros costumavam se referir a escravos dentre seus bens apreendidos pelos senhores, exigindo portanto uma indenização.

Assim como nas disputas entre escravos e forros, também eram comuns as traições entre os cativos. Elas visavam na maior parte das vezes a conquista de privilégios individuais, como alforria ou melhor tratamento.

Uma vez detectada a presença de conflitos entre a camada mais baixa da sociedade, torna-se importante frisarmos, que eles não impediam o

está preso (...) o preto Casemiro escravo de D. Mariana da Cunha". Cod. 330, vol. 4, s/p. 7-12-1819 - ANRJ.

(22) - Cod. 330, vol. 1, s/p. 23-6-1820.

(23) - $57,8 \%$ das vítimas masculinas e $58,7 \%$ das vítimas femininas eram escravos que sofreram crimes violentos. 
desenvolvimento de laços de amizade, e as manifestações culturais entre os escravos. Pelo contrário, estavam presentes tanto no campo como na cidade e foram objeto de muitos estudos (24). A historiografia tem destacado também as reações coletivas dos escravos contra o regime, o papel de liderança dos libertos nas revoltas de escravos, e a proteção que davam aos negros fugitivos.

Procurou-se entretanto mostrar através dos documentos da polícia que apesar dessas relações de solidariedade, comumente discutidas, não faltaram entre os membros das camadas inferiores da sociedade momentos de tensão e ações criminosas. Afinal, era o próprio sistema escravista que os empurrava para elas; através de um contato quase imposto. Convertiam-se em vítimas não só do regime escravista, como vítimas de seus pióprios atos.

POPULAÇÃO TOTAL DA CIDADE DO RIO DE JANEIRO EM 1808 E 1821

$\begin{array}{lcclrr}\text { Ano } & \text { Fogos } & \text { População Livre } & \text { Libertos } & \text { Escravos } & \text { Total } \\ 1808 & 4.000 & 47.090 & 1.000 & 12.000 & 60.000 \\ & & (78,5 \%) & (1,5 \%) & (20 \%) & (100 \%) \\ 1821 & 10.151 & 43.139 & - & 36.182 & 79.321 \\ & & (54,4 \%) & & (45,6 \%) & (100 \%)\end{array}$

PONTES: 1808: John Luccock, Notas sobre o Rio de Janeiro e partes meridionais do Brasil. Belo Horizonte, 1975, p. 28.

1821: Censo de 1821, ANRJ. códice 808 - vol. IV Estatísticas 1790. 1865 .

(24) - Veja-se por exemplo os estudos de Arthur Ramos dentre eles $O$ Folk lore Negro no Brasil, Rio de Janeiro, 1935 e o Negro Brasileiro, 19 vol., São Paulo, 1940 . 